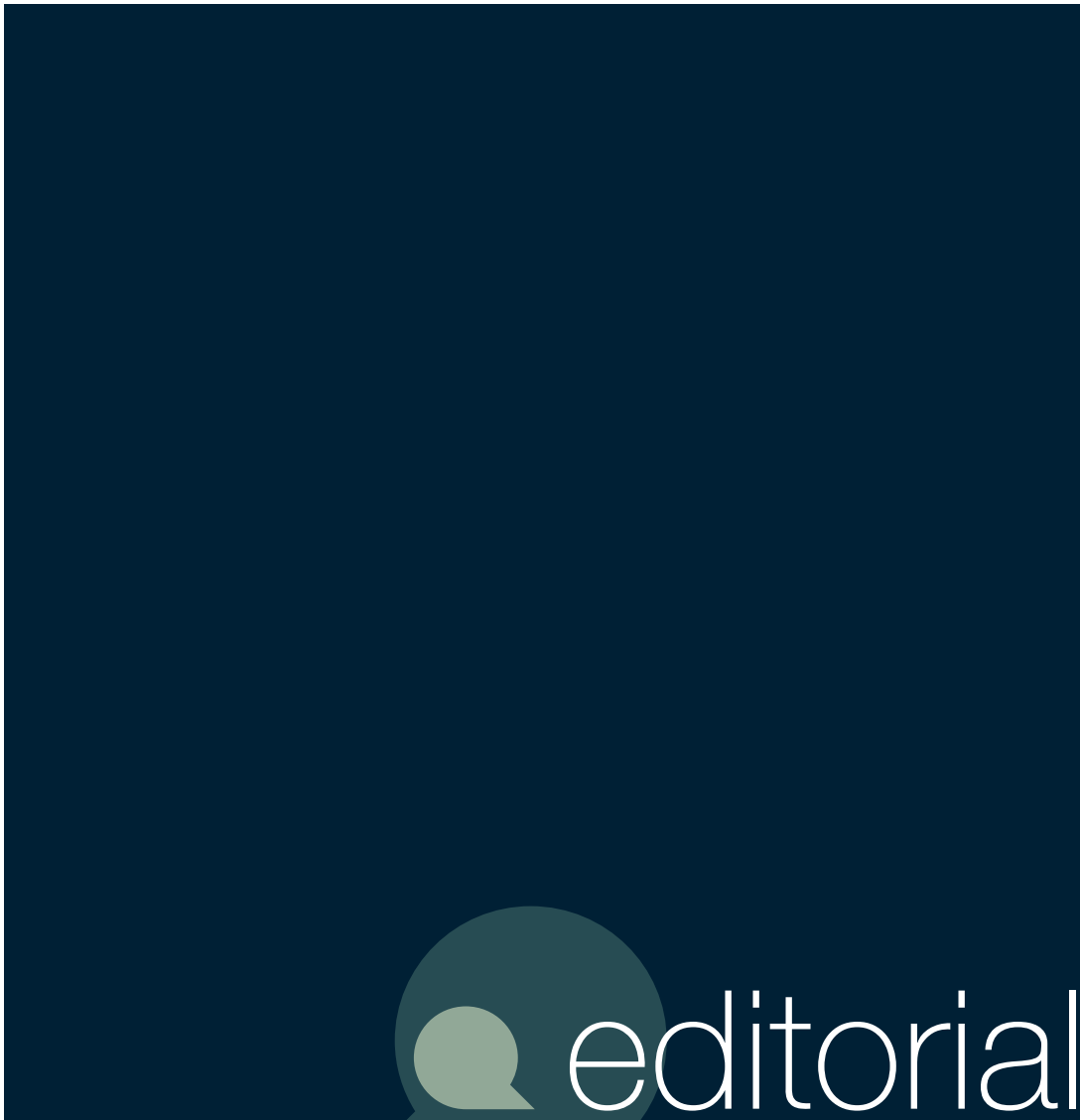




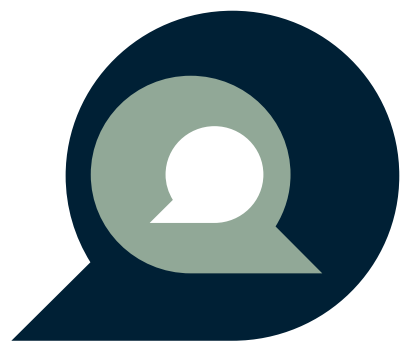

\section{O Lugar da Televisão na Nova Ecologia Audiovisual}

Caras leitoras, caros leitores

Em pleno final de 2020, é impossível contextualizar qualquer fenômeno sem imediatamente relacioná-lo ao complexo e triste momento que atravessamos por conta do Covid-19. Faz já praticamente um ano que o mundo inteiro foi obrigado a reconfigurar seu cotidiano tendo em vista uma pandemia que, como tal, ultrapassa as fronteiras médicas e motiva medos e emoções diversas, tudo intensamente vinculado aos ambientes coletivos. Neste final de 2020, milhares de pessoas ainda evitam sair de casa e se relacionar com outros sujeitos sob o risco iminente de transmitir ou contrair uma doença cruel, que seleciona suas vítimas numa aparente roleta, desafiando as certezas médicas que a modernidade erigiu.

De um modo muito particular, a pandemia evidenciou o lugar central e imprescindível que a televisão ocupa nesse contexto de mudanças sociais capitaneadas por um olhar mais voltado para o interior das residências, onde a televisão histórica e socialmente se consolidou. A pandemia obrigou nossos corpos e mentes a se voltarem mais para a sala de estar, que agora ganha uma roupagem nova, cheia de cabos, tomadas e telas diversas, e que eventualmente se traveste de escritório, sala de aula e pista de dança, para suprir experiências humanas que a modernidade havia sedimentado em empresas, escolas e casas de shows.

Antes da pandemia, a televisão já havia ganhado várias caras (ou telas) para suprir demandas audiovisuais que há muito estavam em curso. Agora, a experiência televisual transformou-se em elemento central 
do cotidiano de uma forma expandida que vai muito além do consumo e dos efeitos dos produtos audiovisuais. Mais do que ser parte integrante de momentos específicos, a televisão se transformou em elo imprescindível com o mundo exterior, muitas vezes sendo a única ou a principal ferramenta de mediação entre mães e filhas, alunes e professores, entre melhores amigues e patrões e funcionários. Já faz quase um ano que milhares de pessoas têm contatos diários com seu espectro de relacionamentos apenas através de uma tela instalada em uma reconfigurada sala de estar.

A televisão hoje se relaciona com o streaming, com as narrativas transmidiáticas, com o consumo global, móvel, portátil e com as redes sociais digitais, além de ser central nas políticas em torno dos conglomerados midiáticos e para a compreensão dos fluxos globais de conteúdo. Mas esse processo também carrega e ratifica convenções, tanto nos hábitos de consumo quanto nas estratégias de produção e circulação. Assistimos a TV fora da TV, mas persistem matrizes culturais e estéticas nessa "nova ecologia": as marcações de serialidade das narrativas ficcionais, as performances corporais inspiradas nos apresentadores televisivos, a permanência de um fluxo de consumo ancorado em uma grade, ainda que sob o manto de novas dinâmicas evidenciadas pelos vídeos on demand, entre muitos outros fenômenos.

Assim, com olhar atento ao fio da história e cada vez mais ciente do contexto singular que atravessamos, este dossiê contempla um conjunto de textos que articula presente e passado, novos e velhos hábitos no sentido de compreender transformações em torno da televisão, ou das televisões, e dos contratos simbólicos firmados com os telespectadores. O Dossiê apresenta duas ênfases centrais de abordagem: a primeira reúne artigos que ressaltam o lugar do streaming como desestabilizador de modos de produção, circulação e consumo da produção ficcional, enquanto a segunda dá conta especialmente de transformações caras ao telejornalismo no novo ecossistema.

Os primeiros cinco artigos lançam luz a diferentes caminhos para a compreensão e análise de novas dinâmicas televisivas da ficção seriada. Em que medida os serviços de Video on Demand aproximam-se da televisão, superam-na ou constituem meio televisivo em si? É a pergunta que nos faz Daniela Conegatti, em "Do Broadcasting ao vídeo on demand: narrativas seriadas e os atravessamentos televisivos". Atenta 
tanto às armadilhas das definições restritas e muitas vezes tecnicistas, que reduzem mudanças do audiovisual a plataformas e modos de distribuição, quanto às caracterizações por demais amplas e imprecisas do fenômeno, a autora constitui um robusto argumento a favor das fronteiras televisivas. Ao dar relevo às aparentes relações paradoxais entre televisão e série, o artigo aposta na ambivalência como possível via produtiva para os estudos de/sobre televisão e de/sobre narrativas seriadas.

Em "Broadcast ourselves: estratégias de produção e distribuição de Cobra Kai (Youtube Premium),' Marcel Vieira Barreto Silva e Leonardo Gonçalves da Silva assumem as noções de "televisão distribuída pela internet", de Lotz, e "Online TV", de Johnson, como chaves interpretativas para vislumbrar possíveis definições da televisão nesta nova ecologia audiovisual. $\mathrm{O}$ debate é adensado pela análise perspicaz das estratégias de produção e distribuição da série Cobra Kai (2018-), produção original do YouTube Premium. Como resultado, os autores sugerem dois caminhos importantes para a compreensão de novas dinâmicas audiovisuais: o investimento em mundos ficcionais construídos em outras obras, como livros, filmes, séries, HQ's, e a datificação da experiência dos espectadores, apontada como elemento central do processo de intersecção entre algoritmos, estratégicas de negócio e criação de conteúdos audiovisuais.

"Modelos de disputa: uma análise dos lugares da Netflix e da HBO no campo da produção audiovisual", de Carolina Santos Fagundes e Tatiana Guenaga Aneas, investe na reflexão das mudanças da televisão na contemporaneidade com interesse específico no campo da produção. Pela abordagem de cunho sociológico, pautada em referenciais de Bourdieu, sobretudo os conceitos de campo, capitais (econômico, cultural, simbólico, social), habitus e trajetória, as autoras detalham estudo comparativo entre a HBO, instituições de prestígio no broadcasting televisivo, e a Netflix, agente emergente de produção audiovisual em streaming, de modo a identificar mudanças processuais nas lógicas de sustentação econômica e reconhecimento social de agentes e instituições do campo audiovisual.

Já o artigo "O fluxo midiático dos animês e seus modelos de distribuição e consumo no Brasil", de Krystal Urbano e Mayara Araújo, atualiza o olhar em torno do papel cultural dos animês no contexto brasileiro ao fazer um debate sobre os modos de distribuição desse conteúdo, desde os anos de 1960, através das emissoras televisivas, até o con- 
temporâneo, quando as plataformas de streaming têm motivado interessantes reconfigurações nos modelos de distribuição desses produtos audiovisuais. Um ponto alto do argumento dá conta do potencial flexível dos animes em se adaptar a diferentes modelos por meio de estratégias que oferecem contrapontos à hegemonia dos desenhos animados produzidos e exportados pelos Estados Unidos.

O trabalho seguinte, "Da utopia democrática ao caos republicano: o lugar da ficção televisiva no reforço da (des)confiança nas instituições políticas estadunidenses", de Melina Meimaridis e Rodrigo Quinan, se ancora em dois dramas políticos - The West Wing e House of Cards -, para fazer uma reflexão vinculada ao potencial de representação de realidade do audiovisual. Em particular, os autores estão interessados em entender os modos de representação de instituições políticas estadunidenses emoldurados por essas duas séries e como elas apresentam duas perspectivas complementares e antagônicas de representação: uma funcional (bastante idealista) e outra disfuncional (e mais contestatória).

A segunda ênfase temática diz respeito às possíveis ressignificações do ethos telejornalístico em novos contextos e dinâmicas digitais. O artigo "As relações do telejornalismo brasileiro no atual ecossistema midiático: uma espécie em adaptação", de Eugenia Mariano da Rocha Barichello e Clarissa Schwartz, busca verificar os movimentos feitos pelo telejornalismo local como reação a uma suposta crise do campo frente ao atual ecossistema midiático. Tendo como objeto empírico o telejornal Bom Dia Rio Grande (RBS TV) e publicações do programa no Facebook, a estudo identifica estratégias de interação e vínculo com a audiência, a partir de tradições culturais/territoriais partilhadas, que reforçam fronteiras cada vez mais porosos entre os meios. Isso impõe ao jornalismo o que as autoras caracterizam como operação autopoiéticas, ou seja, adaptações que se expandem para ir ao encontro da audiência em outras ambiências midiáticas, para além do programa, mas a partir de tradições e convenções (da televisão) já conhecidas e domesticadas.

Por fim, em “'Chamou o VAR!': mesas-redondas na TV, comentário esportivo e o recurso visual na estreia brasileira no Mundial de 2018", Helcio Herbert Neto discute as implicações do uso Video Assistant Referee na cobertura telejornalística, especificamente a partir dos modos como mesas-redondas reagiram à estreia desse recurso em jogos da 
seleção brasileira masculina de futebol em Copas do Mundo. Considerando a imersão desses programas em uma ecologia televisiva marcada pela profusão audiovisual, a análise dá relevo às dimensões visual e retórica do conteúdo dos canais por assinatura SporTV, Esporte Interativo, ESPN e Fox Sports e reforça a noção de gênero televisivo como referencial ainda importante para a compreensão de novas dinâmicas midiáticas. O artigo identifica dois modos distintos de reação ao VAR por parte dos comentaristas, que nos fazem ver disputas sobre o lugar do telejornalismo esportivo nessa ecologia: um modo marcado pelo questionamento sobre a real utilidade da tecnologia para a revisão de marcações da arbitragem; outro relacionado a tendências tradicionais da cobertura televisiva esportiva no Brasil, com a ênfase nas noções de nação, nacionalismo e rivalidade.

Esse conjunto de reflexões aponta para a necessidade, mais do que nunca, de entender o papel preponderante da televisão como locutora e mediadora das experiências contemporâneas características da nossa cultura audiovisual. Evidentemente, não nos referimos à televisão como tecnologia estática ou única, mas como uma forma cultural que transparece nas mais variadas telas com a qual travamos contato com o mundo exterior: dos smartphones aos tablets, das smartTVs às telas de computador. Diante desse contexto de telas, dados, conexões e fluxos audiovisuais intensos, a TV permanece protagonista e reconfigura uma enorme quantidade de fenômenos que atravessam circuitos comunicativos de diferentes dispositivos e ambiências midiáticas. Falar em televisão é englobar reflexões em torno de suas dimensões técnicas, estéticas, sociais, políticas, institucionais, culturais e históricas, que se articulam em ecologias audiovisuais, relacionam o novo e a tradição, as rupturas e as continuidades. Esperamos, com este dossiê, contribuir com esse complexo e instigante debate.

Desejamos uma ótima leitura!

\section{Ariane Holzbach e Juliana Gutmann}




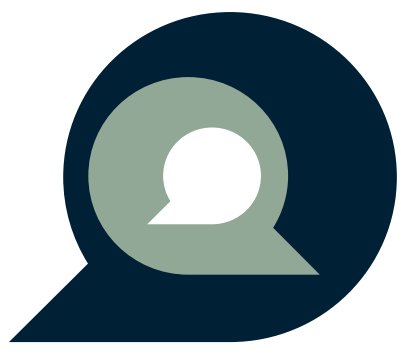

